Department of Dermatology, Cologne, Germany; ${ }^{11}$ University of Michigan, Scleroderma Program, Ann Arbor, United States of America; ${ }^{12}$ Department of Rheumatology, CHU Bordeaux, Bordeaux, France; ${ }^{13}$ University Hospital Basel, Department of Rheumatology, Basel, Switzerland; ${ }^{14}$ Boehringer Ingelheim International $\mathrm{GmbH}$, Inflammation Medicine, Ingelheim am Rhein, Germany; ${ }^{15}$ Boehringer Ingelheim International $\mathrm{GmbH}$, Inflammation Medicine, Ingelheim am Rhein, Germany; ${ }^{16}$ Tulane University Schools of Medicine, Department of Medicine, New Orleans, United States of America: ${ }^{17}$ University Hospital, Department of Rheumatology, Zurich, Switzerland

Background: Current treatments for systemic sclerosis-associated interstitial lung disease (SSc-ILD) are characterised by different attributes such as mode of administration, adverse events (AE) and efficacy. Physicians and patients often have different perspectives on treatments, thus shared decision-making between patients and physicians is essential. An understanding of patients' decision processes when weighing treatment attributes and the trade-offs they are willing to make is important for shared decision-making.

Objectives: The study aimed to 1) identify relevant treatment attributes, 2) elicit patient preferences for these attributes and 3) quantify preference as relative attribute importance (RAl; a higher RAI indicates that more of the variability in patients' responses may be explained by changes in the attribute); and maximum acceptable risk (MAR) of diarrhoea, nausea and/or vomiting (MAR is a trade-off measure that evaluates attributes in risk-equivalences as a unit of measurement). Methods: A discrete choice experiment (DCE) was created, based on a literature review, a patient advisory board, qualitative patient interviews, and a workshop involving SSc-ILD expert physicians. Seven SSc-ILD treatment attributes were identified: 1) mode of administration; 2) shortness of breath; 3) skin tightness; 4) cough; 5) tiredness; 6 ) risk of gastrointestinal tract (GIT) AEs; and 7) risk of serious and non-serious infections. The levels of $A E$ risk were informed by frequencies observed in clinical trials and patient input during the interviews. The DCE was integrated into an online survey, which asked patients to make repeated choices between two alternatives described by varying levels of included attributes. Patients with SSc-ILD were recruited by physician referral from Switzerland, Norway, France, Germany and the USA. DCE data were analysed using a logit model, and RAI and MAR measures were calculated.

Results: A total of 231 patients with physician-confirmed SSc-ILD (mean age $52.6 \pm 13.2$ years; $54 \%$ diagnosed for $>5$ years) completed the survey. Patients with SSc-ILD mostly preferred twice-daily oral treatments $(p<0.001)$ and infusion every $6-12$ months $(p<0.001)$ over monthly infusions. Patients' choices were mostly affected by the risk of GIT AEs (RAI=25\%; $95 \% \mathrm{Cl} 22-28 \%$ ) and risk of infections (RAl=20\%; 95\% Cl 16-24\%). Improvements in shortness of breath and type and severity of cough were jointly more important than improvement in skin tightness $(p<0.001)$.

Patients accepted an additional $21 \%$ risk (95\% Cl $13-29 \%)$ of GIT AEs if they could reduce the frequency of infusions from monthly to 6-12 monthly, or accepted an extra $15 \%(95 \% \mathrm{Cl} 7-23 \%)$ increase in risk if changing to an oral treatment twice daily. Among symptoms, an additional $28 \%(95 \% \mathrm{Cl} 20-36 \%)$ risk of GIT AEs was considered acceptable if the severity of patients' persistent cough was reduced to a level that was easier to tolerate, even if it remained persistent. Similarly, a $37 \%(95 \% \mathrm{Cl} 28-46 \%)$ increase in the risk of GIT AEs was acceptable if it resulted in breathlessness during routine activities rather than breathlessness at rest. Finally, patients were willing to accept an additional $36 \%$ risk $(95 \% \mathrm{Cl} 27-45 \%)$ of GIT AEs if it reduced their risk of non-serious infections from $30 \%$ to $15 \%$ and of serious infections from $10 \%$ to $5 \%$.

Conclusion: This is the first study to quantitatively elicit patients' preferences for attributes of SSc-ILD treatments. Preferences were driven by safety, efficacy and technical considerations. Patients showed willingness to make trade-offs, providing a firm basis for shared decision-making in routine clinical practice.

Disclosure of Interests: Cosimo Bruni Speakers bureau: Actelion, Consultant of: Eli Lilly, Grant/research support from: Gruppo Italiano Lotta alla Scleroderma (GILS), Fondazione Italiana per la Ricerca sull'Artrite (FIRA), New Horizon Fellowship, European Scleroderma Trial and Research (EUSTAR), Foundation for Research in Rheumatology (FOREUM)., Sebastian Heidenreich Consultant of: Sebastian Heidenreich, PhD is employed by Evidera Inc, a business unit of PPD. Evidera is a CRO that offers paid research services to pharmaceutical companies., Ashley Duenas Consultant of: Yes. I am an employee of Evidera which received funding from Boehringer Ingelheim for work related to this study., Anna-Maria Hoffmann-Vold Speakers bureau: Boehringer Ingelheim, Actelion, Roche, Merck Sharp \& Dohme, Lilly, Consultant of: Actelion, Boehringer Ingelheim, Roche, Bayer, Merck Sharp \& Dohme, ARXX, Lilly and Medscape, Grant/research support from: Boehringer Ingelheim, Armando Gabrielli Grant/ research support from: Pfizer Bhering, Yannick Allanore Consultant of: Honorarium received from Boehringer, Medsenic,

Sanofi, Menarini, Grant/research support from: Grants received from Alpine, Ose Immunogenetics, Emmanuel Chatelus: None declared, Jörg H.W. Distler Shareholder of: JHWD is stock owner of 4D Science, Consultant of: JHWD has consultancy relationships with Actelion, Active Biotech, Anamar, ARXX, Bayer
Pharma, Boehringer Ingelheim, Celgene, Galapagos, GSK, Inventiva, JB Therapeutics, Medac, Pfizer, RuiYi and UCB, Grant/research support from: JHWD has received research funding from Anamar, Active Biotech, Array Biopharma, ARXX, aTyr, BMS, Bayer Pharma, Boehringer Ingelheim, Celgene, Galapagos, GSK, Inventiva, Novartis, Sanofi-Aventis, RedX, UCB, Eric Hachulla: None declared, Vivian Hsu Speakers bureau: I am a speaker for Boehringer Ingelheim Pharmaceuticals, Consultant of: with Boehringer Ingelheim Pharmaceuticals, Grant/research support from: Principal Investigator for several clinical trials, currently with Genentech, Corbus Pharmaceutical, and EICOS, Nicolas Hunzelmann Speakers bureau: Boehringer, Roche, Sanofi, Dinesh Khanna Shareholder of: Eicos Sciences, Inc (less than 5\%), Consultant of: Paid Consultant for: Acceleron, Actelion, Abbvie, Amgen, Bayer, Boehringer Ingelheim, CSL Behring, Corbus, Gilead, Galapagos, Genentech/Roche, GSK, Horizon, Merck, Mitsubishi Tanabe Pharma, Sanofi-Aventis, and United Therapeutics, Grant/research support from: Research Grant support from: Immune Tolerance Network, Bayer, BMS, Horizon, Pfizer, Employee of: Leadership/Equity position - Chief Medical Officer, CiviBioPharma/Eicos Sciences, Inc - recieves a stipend for role as Chief Medical Officer, which would technically qualify as emplyoment., Marie-Elise Truchetet Speakers bureau: Abbvie, Lilly, Sobi, Boehringer, Paid instructor for: Lilly, Consultant of: UCB, Sobi, Abbvie, Grant/research support from: UCB, Gilead, Ulrich Walker Shareholder of: Bayer, NASDAQ, MSCI-World ETF's, Speakers bureau: All companies producing pharmaceuticals used in AIDS, Paid instructor for: Roche, Abbvie, Novartis, Consultant of: All companies producing pharmaceuticals used in AIDS, Grant/research support from: Gilead, Abbvie, (in the last two years). Other companies in previous years., Margarida Alves Employee of Boehringer Ingelheim, Nils Schoof Employee of: Employee of Boehringer Ingelheim International $\mathrm{GmbH}$, Lesley Ann Saketkoo Speakers bureau: Boehringer Ingelheim, Actelion, Janssen, Mallinckrodt, United Therapeutics, Consultant of: Actelion, Boehringer Ingelheim, Bayer, Bristol Meyer Squibb, Corbus, EICOS Janssen, Horizon, United Therapeutics, Inc, Grant/research support from: Mallinckrodt, United Therapeutics, Oliver Distler Speakers bureau: Boehringe Ingelheim, Medscape, IQone, Roche, Consultant of: OD has/had consultancy relationship and/or has received research funding in the area of potential treatments for systemic sclerosis and its complications from (last three years):

Abbvie, Acceleron Pharma, Amgen, AnaMar, Arxx Therapeutics, Baecon Discovery, Blade Therapeutics, Bayer, Boehringer Ingelheim, ChemomAb, Corbus Pharmaceuticals, CSL Behring, Galapagos NV, Glenmark Pharmaceuticals, GSK, Horizon (Curzion) Pharmaceuticals, Inventiva, iQvia, Italfarmaco, iQone, Kymera Therapeutics, Lilly, Medac, Medscape, Mitsubishi Tanabe Pharma, MSD, Novartis, Pfizer, Roche, Sanofi, Serodapharm, Topadur, Target Bioscience and UCB. Patent issued "mir-29 for the treatment of systemic sclerosis" (US8247389, EP2331143)., Grant/research support from: Kymera Therapeutics, Mitsubishi Tanabe

DOI: 10.1136/annrheumdis-2021-eular.2112

\section{POS0856 \\ CLINICAL UTILITY OF BREATH-HOLDING TEST FOR MEASURING CARDIOPULMONARY FUNCTION IN PATIENTS WITH SYSTEMIC SCLEROSIS}

J. Yeo ${ }^{1}$, M. H. Kim², J. W. Park ${ }^{2}$, J. K. Park ${ }^{2,3}$, E. B. Lee ${ }^{2,3,4} .{ }^{1}$ Seoul National University Hospital, Division of Rheumatology, Department of Internal Medicine, Seoul, Korea, Rep. of (South Korea); ${ }^{2}$ Seoul National University Hospital, Division of Rheumatology, Department of Internal Medicine, Seoul, Korea, Rep. of (South Korea); ${ }^{3}$ Seoul National University College of Medicine, Department of Internal Medicine, Seoul, Korea, Rep. of (South Korea); ${ }^{4}$ Seoul National University, Molecular Medicine and Biopharmaceutical Sciences, Graduate School of Convergence Science and Technology, Seoul, Korea, Rep. of (South Korea)

Background: Interstitial lung disease (ILD) and pulmonary arterial hypertension (PAH) are major causes of death in systemic sclerosis (SSc). Six-minute-walk test (6MWT) is a standard outcome measure for exercise capacity in cardiopulmonary diseases. However, the results of 6MWT may not reflect real cardiopulmonary function of SSc patients in whom musculoskeletal system is frequently inflicted. Objectives: This study aimed to evaluate the clinical utility of breath-holding test (BHT) in evaluating cardiopulmonary function in SSc patients, as compared with 6MWT.

Methods: Seventy-two patients with SSc were prospectively enrolled and underwent BHT and 6MWT with measurement of Borg score and Scleroderma Health Assessment Questionnaire (SHAQ). Data on diffusing capacity for carbon monoxide (DLCO, \%), forced vital capacity (FVC, \% and liters), and ejection fraction and pulmonary arterial systolic pressure (PASP) measured by transthoracic echocardiography (TTE), were also collected. For BHT, participants were required to make a maximum expiration followed by a maximum inspiration and to hold the breath as long as possible at maximum inspiratory level. This procedure was repeated three times, with 5-minute intervals. 6MWT was performed according to the American Thoracic Society guidelines. Pearson's correlation test was applied to demonstrate the relationship between BHT results and each clinical parameter. 
Results: Among 72 (66 female) patients, mean (SD) age was 57.1 (11.1) years, modified Rodnan skin score 10.6 (10.5), SHAQ 0.64 (0.61) and 6MWT distance 473.5 (95.5) m. Mean BHT time was 35.05 (14.90) sec at the first time, 38.92 (16.14) sec at the second time, and 41.11 (17.71) sec at the third time. The BHT time showed a statistically significant negative correlation with Borg scale (pretest, $r=-0.336, p=0.002$; post-test, $r=-0.252, p=0.034$; Figure 1 and Table 1 ), while 6MWT showed a negative correlation with only post-test Borg scale (pretest, $r=-0.113 p=0.343$; post-test, $r=-0.351 p=0.002$; Table 1). The BHT time was positively correlated with DLCO $(\%, r=0.409, p<0.001)$ and FVC (liters, $r$ $=0.402, p<0.001)$ (Table 1). We also found a statistically significant correlation between BHT time and SHAQ score $(r=-0.451, p<0.001$; Table 1). However, EF and PASP by TTE showed no significant relationship with BHT time (EF, $r=$ $-0.108, p=0.374 ;$ PASP, $r=-0.246, p=0.054$; Table 1)

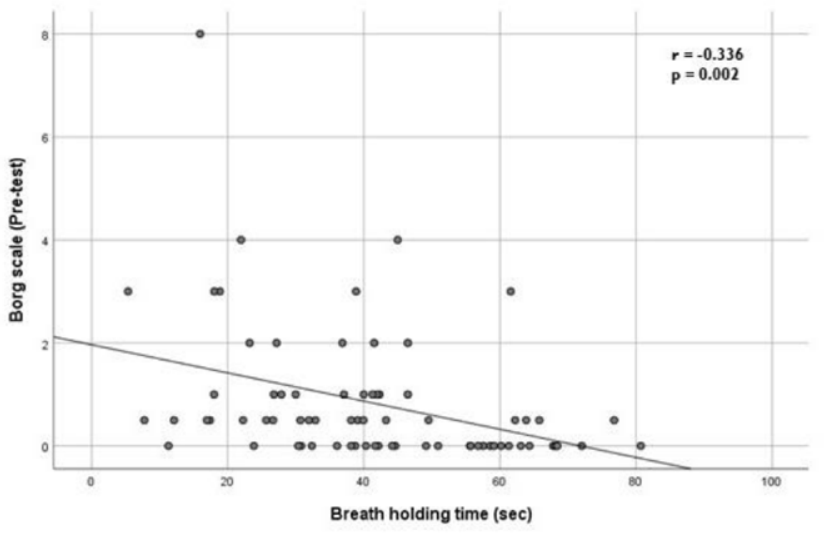

Figure 1. Association of Borg dyspnea scale with breath-holding time.

Table 1. Pearson's correlation coefficients $(r)$ for the relation between $\mathrm{BHT}$ and clinical parameters in comparison to 6MWT.

Pre-test Post-test DLCO FVC FVC FVC EF PSAP SHAQ Borg scale Borg scale $\quad$ (score) $(\%) \quad(\mathrm{L}) \quad(\%) \quad / \mathrm{DLCO} \quad(\%) \quad(\mathrm{mm} \mathrm{Hg})$

BHT (sec) $-0.366^{* *} \quad-0.252^{*} \quad 0.409^{* * *} 0.402^{* *} 0.191 \quad-0.244^{* * *}-0.108 \quad-0.246 \quad-0.451^{* * *}$

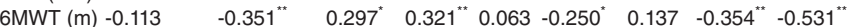

$\overline{\mathrm{BHT}}$, breath-holding test; 6MWT, 6-minute-walk test; DLCO, diffusing capacity for carbon monoxide; FVC, forced vital capacity; EF, ejection fraction estimated by transthoracic echocardiography; SHAQ, Scleroderma Health Assessment Questionnaire.

${ }^{\star} \mathrm{p}<0.05,{ }^{* \star} \mathrm{p}<0.01,{ }^{\star \star *} \mathrm{p}<0.001$

Conclusion: The BHT is a simple, safe, and less time-consuming test, reflective of pulmonary parameters and SHAQ, as compared with 6MWT. Our results suggest that the BHT might be a useful surrogate marker of cardiopulmonary capacity in SSc patients.

\section{REFERENCES:}

[1] Villalba WO, Sampaio-Barros PD, Pereira MC, Cerqueira EM, Leme CA, Jr., Marques-Neto JF, et al. Six-minute walk test for the evaluation of pulmonary disease severity in scleroderma patients. Chest. 2007;131(1):217-22.

[2] Garin MC, Highland KB, Silver RM, Strange C. Limitations to the 6-minute walk test in interstitial lung disease and pulmonary hypertension in scleroderma. J Rheumatol. 2009;36(2):330-6.

[3] Barnai M, Laki I, Gyurkovits K, Angyan L, Horvath G. Relationship between breath-hold time and physical performance in patients with cystic fibrosis. Eur J Appl Physiol. 2005;95(2-3):172-8.

Acknowledgements: This study would not have been possible without help from research assistant, Sung-Soon Cho.

Disclosure of Interests: Jina Yeo: None declared, Mi Hyeon Kim: None declared, Jun Won Park: None declared, Jin Kyun Park: None declared, Eun Bong Lee Consultant of: Pfizer, Grant/research support from: GC Pharma and Handok Inc. DOI: 10.1136/annrheumdis-2021-eular.2273

\begin{tabular}{l|l}
\hline POS0857 & IMMUNOSUPPRESSANTS (CYCLOPHOSPHAMIDE AND \\
MYCOPHENOLATE MOFETIL) VERSUS RITUXIMAB \\
A SINGLE-AGENT THERAPY IN SCLERODERMA- \\
RELATED INTERSTITIAL LUNG DISEASE: REAL \\
CLINICAL PRACTICE
\end{tabular}

O. Koneva $^{1}$, L. P. Ananyeva ${ }^{1}$, L. Garzanova ${ }^{1}$, O. Desinova ${ }^{1}$, O. Ovsyannikova ${ }^{1}$, M. Starovoytova ${ }^{1}{ }^{1}$ V.A. Nasonova Research Institute of Rheumatology, Laboratory of Microcirculation and Inflammation, Moscow, Russian Federation
Background: Although interstitial lung disease (ILD) occurs in the majority of patients with systemic sclerosis (SSc), treatment options for this manifestation is empirical and at present consists of Cyclophosphamide (CyP) or Mycophenolate Mofetil (MMF). However, the immunosuppressants (IS) use leads to rather limited improvement of ILD and is associated with many adverse reactions. The search for novel, more efficacious agents has been continued, such as attracting much attention RTM. However, the limited number of RTM-treated patients, considerably different dose regimens, cumulative doses, and observation periods does not allow univocal conclusions on RTM efficacy or definitive recommendations on RTM use in the patients with SSc.

Objectives: To compare the impact of IS and RTM a single-agent therapy on SSc clinical manifestation and activity, and the safety of these agents in the open-label prospective non-randomized study.

Methods: 116 patients with the confirmed SSc diagnosis and ILD evidence based on MSCT findings were enrolled into the study. All patients received low and moderate-dose glucocorticoids regimens. Group $A(n=35)$ received RTM as a single therapy agent for $13.3 \pm 2.3$ months at total dose $1.35 \pm 0,5 \mathrm{~g}$ (the patient's average age was $45.0 \pm 15$ years, with female proportion $80 \%$; SSc duration $6.3 \pm 2.3$ years; diffused/localized forms $1.3 / 1)$. Group $B(n=36)$ received parenteral CyP for $12 \pm 6$ months at total dose $10.6 \pm 5 \mathrm{~g}$ (the average age $47 \pm 12$ years females $92 \%$, SSc duration $5.0 \pm 4.8$ years, diffused/localized forms $1.6 / 1$ ). Group $C(n=45)$ received MMF for $12 \pm 6$ months at a dose of 2 grams per day (the average age $49 \pm 13$ years, females $91 \%$, SSc duration $7.1 \pm 5$ years, diffused/localized forms 1/1.3). The time courses of FVC, modified skin count (mRss, points), activity index (EScSG, points) were assessed into the study.

Results: In Groups A, B and C the therapy was associated with significan decrease in mRss ( $p=0.02,0.008,0.007$, respectively) and EScSG ( $p=0.00017$ $0.000165,0.01$, respectively)

Evaluation of FVC time course revealed significant FVC increase only in Groups $A(p=0.002)$ and $B(p=0.034)$, with median increment about $5 \%$.

In Groups A and B 10\% FVC increase was found in the third of the patients thus exceeding respective parameter twice in Group $\mathrm{C}(\mathrm{p}=0.15$ and 0.008 , respectively). The patient percentage with FVC decrease by $\geq 10 \%$ did not differ significantly between groups.

The therapy was better tolerated in RTM-treated group: during RTM therapy adverse reactions emerged in lower proportion of the patients $(4 / 11 \%)$ compared with CyP (19/53\%, p=0.0000) and MMF-treated group (12/27\%, $p=0,5)$.

\begin{tabular}{llll}
\hline Parameters & Group A & Group B & Group C \\
\hline $\begin{array}{l}\text { Activity Index } 1 \\
M \pm S D\end{array}$ & $2.8 \pm 1.4^{*}$ & $3.2 \pm 1.9^{*}$ & $1.9 \pm 1.5^{*}$ \\
$\begin{array}{l}\text { Activity Index } 2 \\
M \pm S D\end{array}$ & $1.4 \pm 1.2^{*}$ & $1.4 \pm 1.2^{*}$ & $1.2 \pm 0.9^{*}$ \\
Skin count 1 & & & \\
$M \pm S D$ & $11.5 \pm 9.5^{*}$ & $11.2 \pm 7.9^{*}$ & $7.5 \pm 6.9^{*}$ \\
Skin count 2 & & & \\
$M \pm S D$ & $8.2 \pm 6.2^{*}$ & $7.9 \pm 6.8^{*}$ & $4.8 \pm 3.9^{*}$ \\
FVC $1 M \pm S D$ & & & \\
FVC 2 $M \pm S D$ & $78.7 \pm 20.0^{*}$ & $80.5 \pm 20.1^{*}$ & $90.3 \pm 20.8$ \\
$\Delta$ FVC $\%$ & $84.2 \pm 20.0^{*}$ & $85.8 \pm 20.4^{*}$ & $92.2 \pm 21.0$ \\
& 5.3 & 5.7 & 1.9 \\
FVC increment by $\geq 10 \%, \mathrm{n} / \%$ & {$[0.8 ; 11.1]$} & {$[0 ; 11.2]$} & {$[-3.5 ; 6.0]$} \\
FVC decrement by $\geq 10 \% \mathrm{n} / \%$ & $2 / 5.7$ & $14 / 31$ & $6 / 13.3$ \\
& & $2 / 4.4$ & $4 / 8.9$
\end{tabular}

Notes: in Parameters column $1=$ before treatment, $2=$ after treatment $M \pm S D=$ mean value and standard deviation; * = significant difference between the vales measured before and after the treatment

Conclusion: All agents effectively alleviated skin induration and EScSG, but only RTM and CyP significantly improved FVC. The RTM single therapy was bette tolerated compared to IS. The study findings substantiate potential use an RTM single therapy both as a first-line agent for ILD treatment in the patients with a progressive course of ILD damage SSc, and in the event of CyP inefficacy of poo tolerability. The MMF use is more preferable in patients with less pronounced ILD. Disclosure of Interests: None declared

DOI: 10.1136/annrheumdis-2021-eular.2288

\section{POS0858 1 POTENTIAL EFFICACY PREDICTORS OF ANTI-B- CELL THERAPY IN THE PATIENTS WITH SYSTEMIC SCLEROSIS ASSOCIATED WITH INTERSTITIAL LUNG DISEASE}

O. Koneva $^{1}$, L. P. Ananyeva ${ }^{1}$, L. Garzanova ${ }^{1}$, O. Desinova ${ }^{1}$, O. Ovsyannikova ${ }^{1}$, M. Starovoytova ${ }^{1} .{ }^{1}$ V.A. Nasonova Research Institute of Rheumatology, Laboratory of Microcirculation and Inflammation, Moscow, Russian Federation

Background: Rituximab (RTM) is considered as a promising therapeutic agent for treatment of With Interstitial Lung Disease (ILD) in the patients with systemic sclerosis (SSc). However, the limited number of RTM-treated patients, considerably 